\title{
Lung Cancer pN1 TNM Finding
}

National Cancer Institute

\section{Source}

National Cancer Institute. Lung Cancer pN1 TNM Finding. NCI Thesaurus. Code C60974.

Lung cancer with metastasis to ipsilateral peribronchial and/or ipsilateral hilar lymph

nodes, including intrapulmonary nodes involved by direct extension of the primary tumor.

(from CAP Lung Cancer Protocol--January 2005 Revision) 